\title{
Characterization of a Selective Surface Based on Chromium, Iron and Aluminum Oxides for Application in Solar-Thermal Collectors
}

\author{
Kaio Hemerson Dutra ${ }^{a}$ (D), Francisco Nivaldo Aguiar Freire ${ }^{a}$, Diego Caitano Pinho ${ }^{a}$ (D), \\ Felipe Alves Albuquerque Araújo ${ }^{a}$ (D) \\ ${ }^{a}$ Universidade Federal do Ceará, Laboratório de Filmes Finos em Energia Renovável, Fortaleza, CE, Brasil.
}

Received: September 22, 2021; Revised: November 20, 2021; Accepted: December 08, 2021

\begin{abstract}
The depletion of conventional energy sources and the concern with the environmental impacts of the use of fossil fuels sparked interest in researching new energy sources and improving existing processes. In this context, the solar energy presents itself as one of the most promising energy sources on the planet, given its wide availability and applicability in thermal processes. However, its use still represents a great technological and economic challenge, because many systems that use this energy still have low efficiency and high cost, which makes them uncompetitive in competition with systems using other energies. With that, the search for the improvement of the processes awakens the researches in more adequate and cheaper materials, which represents a great scientific potential in the evolution of these technologies. Thus, the present work proposes to obtain and analyze a selective surface for applications in solar-thermal collectors, using CRFO (compound formed by chromium and iron oxides), varying the percentage by weight, and then mixed with aluminum oxide. For the tests, an experimental bench was built to simulate a flat plate solar-thermal collector in real operating conditions. Some characterizations were carried out, such as: techniques scanning electron microscopy (SEM), infrared analysis and UV-VIS absorptivity determination, as well as the graphs with surface temperatures and with radiation during the tests in the Sun for the composite (CRFO and aluminum oxide) and for the commercial surface (MRTiNOX). With the results obtained, it was verified in the field test that one of the produced selective surfaces obtained a result of absorptivity of 0.94 and 0.0349 of emissivity, which is close to that of the commercial surface. The results were confirmed in the characterization by UV-VIS, which showed high absorptivity values in the visible light range.
\end{abstract}

Keywords: Solar energy, selective surface, efficiency, collectors.

\section{Introduction}

The use of solar energy is already a reality, however, although it is an available and abundant energy source, the systems for capturing and transforming this energy are still at an economic disadvantage compared to processes that use conventional energy, which opens up great possibilities for research into the improvement of processes and the use of materials that provide increased efficiency and reduced costs ${ }^{1}$.

In the specific case of solar-thermal energy, solar radiation is absorbed by solar-thermal collectors, these are composed of surfaces capable of absorbing solar radiation and converting it into thermal energy, transporting it by conduction. The absorbed radiation is conducted by the absorbers and can heat working fluids, liquids or gases. Systems using solar-thermal energy can be applied for heating water in homes, hotels and hospitals, other systems can be used for drying and dehydrating fruits in the food industry and desalination of seawater ${ }^{2}$.

In practical applications of high efficiency, for the conversion of radiation from the sun into thermal energy, for heating working fluids, solar-theraml collectors are used with coatings on their radiation-receiving surfaces. This coating can consist

*e-mail:kaiohdutra@gmail.com of a black or selective surface, which is deposited on a base material, absorbing solar radiation and playing an important role in terms of absorption and emission of radiation, directly influencing the thermal transformation process. Therefore, it is necessary that this surface absorbs radiation well in the solar spectrum (ultraviolet and visible) and, at the same time, has a low emissivity, avoiding heat loss to the environment. The selective surface is usually composed of a thin film applied on a thermally conductive substrate, which can be proceded by an antioxidant layer and followed by an anti-reflective layer, in direct contact with the environment ${ }^{3,4}$.

The purpose of using selective surfaces, more efficient than black surfaces, in the base material (material that conducts thermal energy) is to maximize energy absorption, but without providing large emissions of thermal radiation to the environment, so that the net energy gain is increased, thus improving the efficiency of the system ${ }^{5}$.

The objective of this work is to synthesize, analyze and test selective surfaces for application in flat plate solar-thermal collectors using CRFO (compound formed by chromium and iron oxides) and aluminum oxide. The goal is to obtain a surface similar to or superior to selective surfaces already on the market. 


\section{Materials and Methods}

\subsection{Production of $C R F O$}

The preparation of the material, which was used, was based on the methodology proposed by ${ }^{6}$ to obtain the CRFO100 (Cr0,75Fe1,25O3). The procedure consisted of a mixture of $127,3 \mathrm{~g}$ of iron oxide $\mathrm{Fe}_{2} \mathrm{O}_{3}$ (Aldrich, 99+\%) with $72,7 \mathrm{~g}$ chromium oxide $\mathrm{CR}_{2} \mathrm{O}_{3}$. The iron and chromium oxides were duly ground in a planetary mill using zirconium balls, for this purpose, polyamide (technil) pans were used. After milling, the oxides were mixed and a mixture of $200 \mathrm{~g}$ was thus obtained. After mixing, the material was subjected to a heat treatment at a temperature of $1300^{\circ} \mathrm{C}$ with a heating rate of $1^{\circ} \mathrm{C}$ per minute, maintaining the maximum temperature for 5 hours. The procedure was carried out in a muffle oven.

After the calcination process, which takes place during the 5 hours of permanence at a temperature of $1300^{\circ} \mathrm{C}$, the oven was turned off and put to cool in a natural way, avoiding high cooling rates. As a result, the CRFO100 is obtained $\left(\mathrm{Cr}_{0,75} \mathrm{Fe}_{1,25} \mathrm{O}_{3}\right)$, iron and chromium have the same oxidation number, $\mathrm{Fe}^{3+}$ and $\mathrm{Cr}^{3+}$, and thus share the same site in the compound ${ }^{6,7}$.

As shown in Figure 1, the compound obtained has a very high granulation, which would make the manufacturing process of selective surfaces difficult.

A high granulation can disrupt the production process of selective surfaces, leaving them very rough, making the process of depositing on substrates difficult. In this way, the CRFO was ground by a mortar and pestle, thus obtaining a material with lower granulation. The ground material was submitted to a granulometry sieve, in order to separate the CRFO in homogeneously granulated portions. For manufacturing tests on selective surfaces, the following granulations were separated: 42 mesh $(0.355 \mathrm{~mm}$ sieve opening), 100 mesh $(0.15 \mathrm{~mm}$ opening) and 170 mesh $(0.09 \mathrm{~mm} \text { sieve opening })^{8}$.

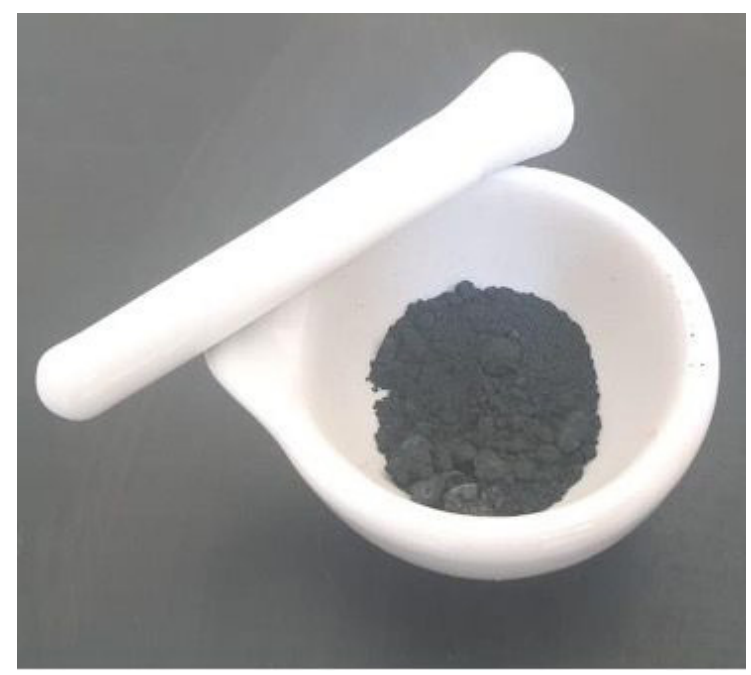

Figure 1. CRFO after calcination.

\subsection{Surface production}

The composites were produced using CRFO and aluminum oxide, being combined in the following proportions: $25 \%$ $75 \%, 50 \%-50 \%$ and $75 \%-25 \%$. All samples were produced with 100 mesh CRFO granulation, due to the difficulty of handling the CRFO obtained with a 170 mesh sieve, because, due to the grain size, much of it was lost in the air in the process, and with the CRFO obtained with 42 mesh sieve, the surfaces produced showed roughness.

The samples were made by mixing the powder of each component, so it was necessary, to make their adhesion to the base material, the use of binders, transforming them into elements with viscous characteristics and adherent to metallic surfaces. The binder used was the epoxy adhesive MRAraudite, using 35\% in weight relative to the total sample $^{9}$ and $^{10}$.

To finish the deposited compound, was added $\mathrm{B}_{2} \mathrm{O}_{3} / \mathrm{Bi}_{2} \mathrm{O}_{3}$ flux(1:1 molar mixture of boron-bismuth) was added in a proportion of $3 \%$ by weight relative to the total sample. The composition of each surface produced is shown in Table 1.

After obtaining the compounds, the deposition was made on a copper substrate $(4 \mathrm{~cm} \times 2 \mathrm{~cm}$ plate, with approximate thickness of $0.3 \mathrm{~mm}$ ), through the process known as screen printing, in which a spatula is used to spread them about this. Subsequently, the surfaces received heat treatment (sintering) in a resistive oven. Several tests were carried out until the ideal parameters were found for the samples to adhere completely, homogeneously and with little roughness to the copper substrate. The sintering parameters are shown in Figure 2.

The heating process from ambient temperature to $50^{\circ} \mathrm{C}$ at a rate of $0.5^{\circ} \mathrm{C} / \mathrm{min}$; stay at $50^{\circ} \mathrm{C}$ for 20 minutes; heating from $50^{\circ} \mathrm{C}$ to $100^{\circ} \mathrm{C}$ at a rate of $0.5^{\circ} \mathrm{C} / \mathrm{min}$; stay at $100^{\circ} \mathrm{C}$ for 20 minutes; heating from $100^{\circ} \mathrm{C}$ to $150^{\circ} \mathrm{C}$ at a rate of $0.5^{\circ} \mathrm{C} / \mathrm{min}$; stay at $150^{\circ} \mathrm{C}$ for 5 hours; cooling from $150^{\circ} \mathrm{C}$ to ambient temperature inside the oven.

\subsection{Test brench}

To perform the evaluation of selective surfaces, was constructed a field test bench, Figure 3. The bench was constructed of $2.5 \mathrm{~cm}$ thick muiracatiara wooden, with a MRVivix float glass cover, colorless, tempered, measuring $1 \mathrm{mx} 12.6 \mathrm{~cm}$ and $4 \mathrm{~mm}$ thick and insulated at the bottom with glass wool $11.5 \mathrm{~cm} \times 8.5 \mathrm{~cm}$ and $5 \mathrm{~cm}$ thickness. The bench has nine compartments for sheltering the selective surfaces that are deposited above the insulation of each compartment. The bench simulates real operating conditions of the fins of a thermal solar-thermal collector.

Table 1. Composition of selective surfaces obtained in percentage terms.

\begin{tabular}{cccc}
\hline Components & Surface 1 & Surface 2 & Surface 3 \\
\hline CRFO [\%] & 15.5 & 31 & 46.5 \\
\hline aluminum oxide [\%] & 46.5 & 31 & 15.5 \\
\hline Flux [\%] & 3 & 3 & 3 \\
\hline MRAraudite [\%] & 35 & 35 & 35 \\
\hline Total mass [g] & 3.2 & 3.2 & 3.2 \\
\hline
\end{tabular}




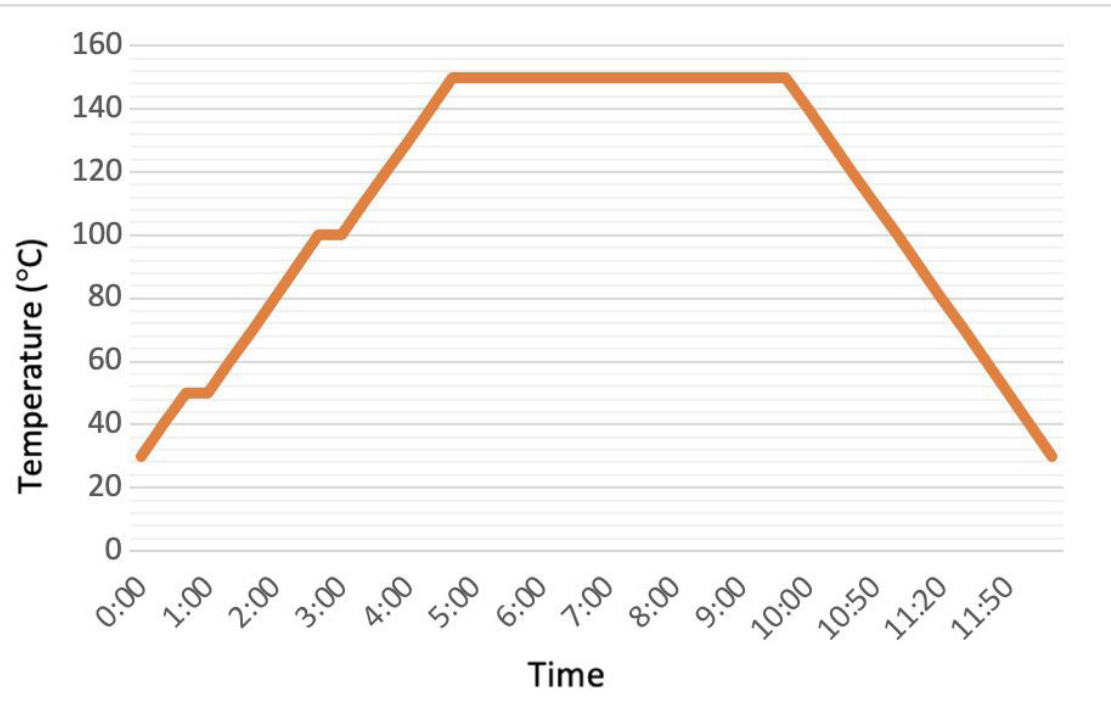

Figure 2. Sintering parameters of selective surface using a resistive kiln.

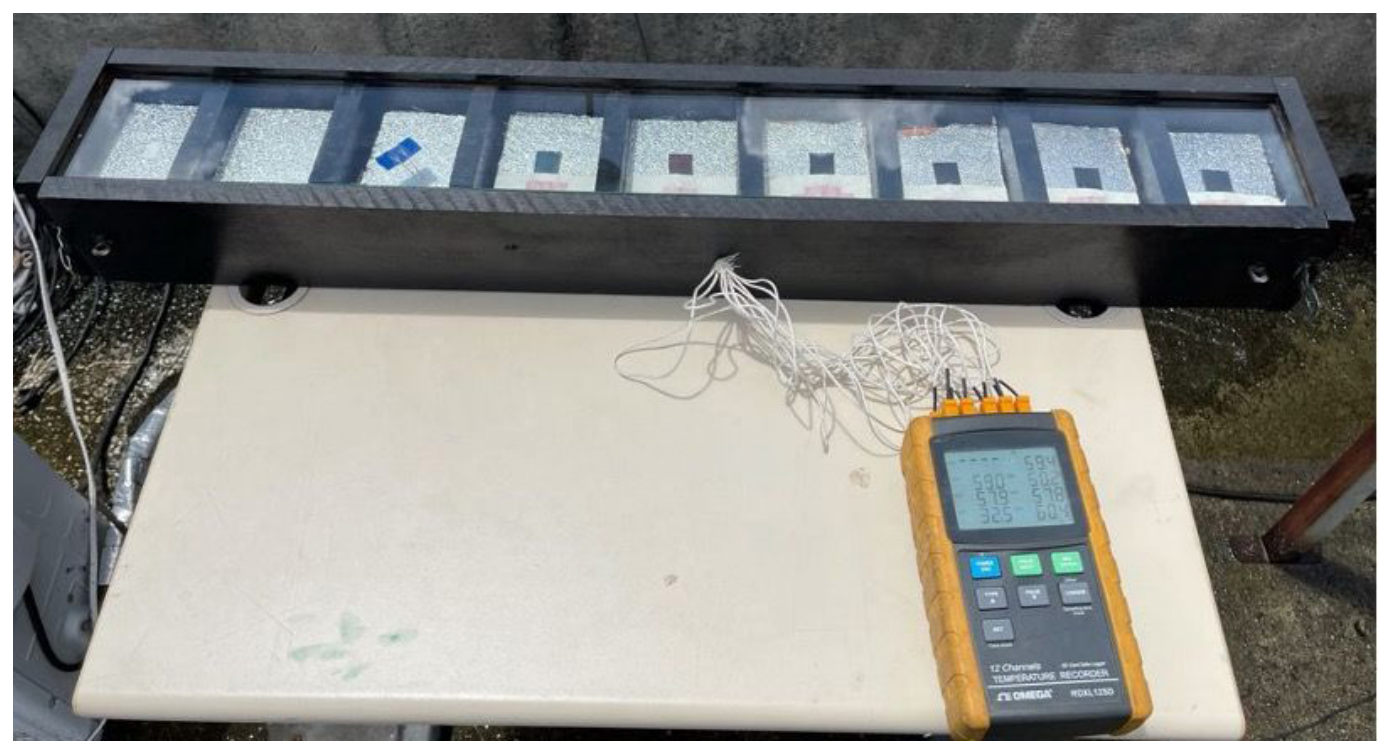

Figure 3. Test brench.

To measure the temperature of the selective surfaces, the environment, glass covering and insulation, type " $\mathrm{k}$ " thermocouples were installed. To measure the solar radiation, an MREppley Horizontal Pyranometer was used. To record and store the data obtained during the test, an Omega datalogger was used.

\subsection{Energy balance in the test bench}

To analyze and compare the performance of the selective surfaces, an energy balance was performed in a bench test. Figure 4 shows the representation of the energy balance in the system ${ }^{11,12}$.

The input energy $\left(Q_{i n}\right)$, Equation 1, is the net solar radiation $\left(Q_{s o l}\right)$, that passes through the glass cover, with transmissivity $\tau_{v}$, and is absorbed by the selective surface, with absorptivity $\alpha_{s}{ }^{13}$.

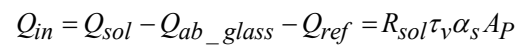

Where $Q_{a b \_g l a s s}$ represents the heat absorbed by the glass, $Q_{r e f}$ the reflective heat by the selective surface, Rsol the solar irradiation and Ap the selective surface area.

The output energy $\left(Q_{\text {out }}\right)$, Equation 2, is related to the thermal losses through the collector by thermal radiation $\left(Q_{\text {rad }}\right)$, convection $\left(Q_{\text {conv }}\right)$ and conduction $\left.\left(Q_{\text {cond }}\right)\right)$.

$$
Q_{\text {out }}=Q_{\text {rad }}-Q_{\text {conv }}-Q_{\text {cond }}
$$




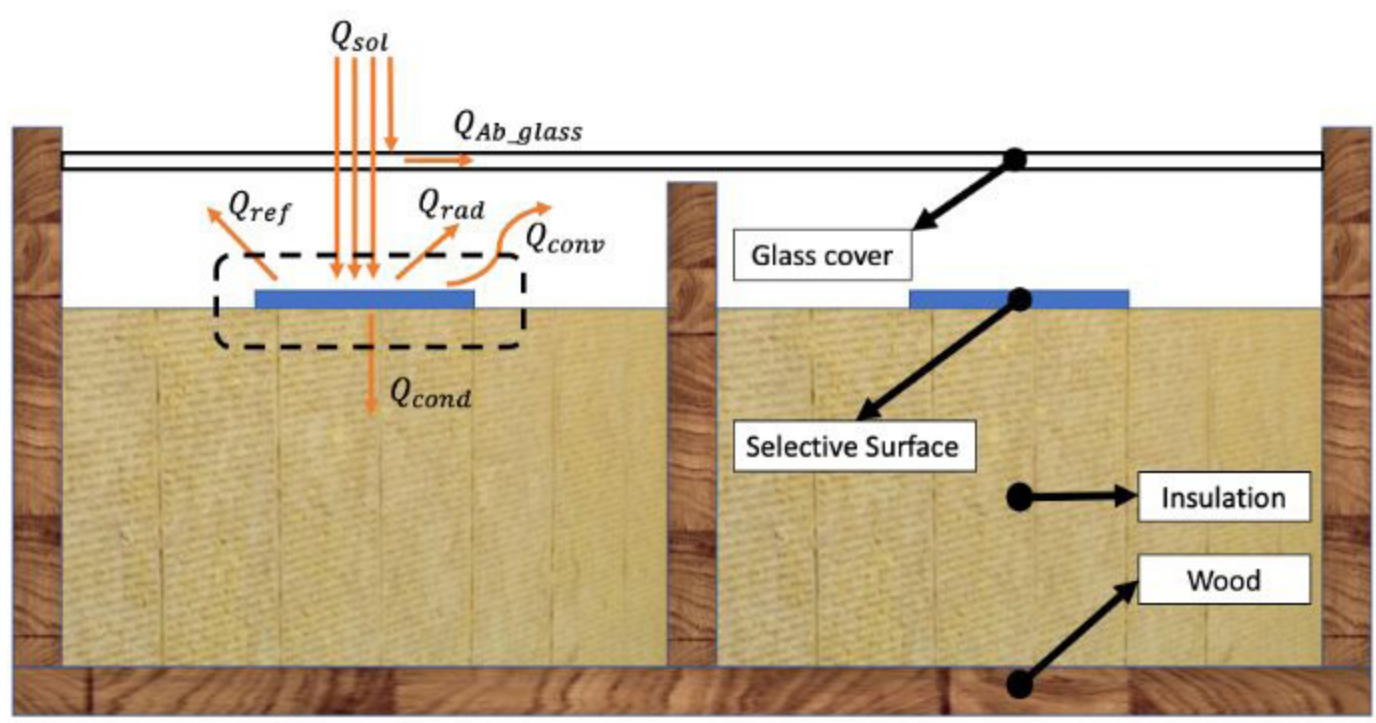

Figure 4. Representation test bench.

The Equation 3 gives the radiation heat loss. Where $\sigma$ is the Stefan-Boltzman constant $\left(\sigma=5,6710^{-8} \mathrm{~W} / \mathrm{m}^{2} k^{4}\right)$, $\varepsilon$ is the emissivity of the selective surface, $T_{P}$ is the plate temperature and $T_{b}$ is the temperature near to the outer wall of the structure

$Q_{\text {rad }}=\varepsilon A_{P} \sigma\left(T_{P}^{4}-T_{b}^{4}\right)$

The Equation 4 gives the natural convection heat loss in the compartment between the selective surface and the glass cover. Where $h$ is the heat transfer coefficient by convection and $T_{c g}$ is the temperature of the glass cover.

$Q_{\text {conv }}=h A_{P}\left(T_{P}-T_{c g}\right)$

The energy loss by conduction occurs mainly through thermal insulation, as shown in Figure 4. Equation 5 represents the energy losses by conduction. Where: $\mathrm{L}$ is the thickness of the insulation and $\mathrm{K}$ is the thermal conductivity.

$Q_{\text {cond }}=\left(\frac{K}{L}\right) A_{P}\left(T_{P}-T_{b}\right)$

The energy balance for the control volume shown in Figure 3 is given by Equation 6. Where the heat generated $\left(Q_{\text {generated }}\right)$ and the heat accumulated $\left(Q_{\text {accumulated }}\right)$ are zero because there is no internal heat generation and operate in permanent regime.

$Q_{\text {in }}+Q_{\text {generated }}=Q_{\text {out }}+Q_{\text {accumulated }}$

$Q_{\text {in }}=Q_{\text {out }}$

Then, substituting Equations 1 to 5 into Equation 6 and adopting the proposed considerations, the energy balance equation can be written as represented in Equation 7.
$R_{\text {sol }} \tau_{v} \alpha_{S} A_{P}=\varepsilon A_{P} \sigma\left(T_{P}^{4}-T_{b}^{4}\right)+h A_{P}\left(T_{P}-T_{c g}\right)+$

$\left(\frac{K}{L}\right) A_{P}\left(T_{P}-T_{b}\right)$

From the energy balance performed, it is possible to calculate the absorptivity and emissivity properties of selective surfaces based on data obtained in field tests. However, it is necessary to use Equation 8, which corresponds to the useful energy ( $Q_{u s e f u l}$ ) supplied by the system (solar-thermal collector) to the working fluid ${ }^{5}$. Where $T_{a}$ is the ambient temperature.

$Q_{\text {useful }}=A_{P} R_{\text {sol }} \tau_{v} \alpha_{s}-A_{p} U_{l}\left(T_{P}-T_{a}\right)$

For the system shown in Figure 3, there is no use of thermal fluid, thus $Q_{u s e f u l}=0$. Therefore, Equation 8)can be written as represented in Equation 9.

$U_{l}=\frac{R_{s o l} \tau_{v} \alpha_{s}}{\left(T_{P}-T_{a}\right)}$

\subsection{Performed test}

To produce selective surfaces, several tests were carried out, still in the production phase, in order to obtain the ideal parameters for the heat treatment (sintering), as presented in section 2.2. Thus, in section 3.1 we will present some of the parameters that were tested and did not get the expected surface. For characterization and verification of the performance of the new selective surfaces obtained, the following tests were performed:

1. Absorptivity graphs, in the range of $190 \mathrm{~nm}$ to $900 \mathrm{~nm}$, obtained by the analysis of the selective 
surfaces deposited in glass, realized in a Cary Series UV-Vis Spectrophotometer;

2. Infrared analysis, with $\mathrm{KBr}$ inserts, in the Shimadzu apparatus, IRTracer-100 model, in the range of 400 to $4000 \mathrm{~cm}-1$, in order to determine if any composites were formed after the surface preparation in the resistive kiln;

3. Verification of the morphological structure and chemical composition resulting from the synthesization of the material by means of EDX micro scanning electron microscopy (SEM);

4. Performance tests of the selective surfaces in the test bench in real environmental conditions, with measurements of temperature, absorptivity and emissivity.

\section{Results and Discussions}

\subsection{Heat treatment}

The purpose of the heat treatment was for the binder to evaporate and, thus, the sintering process of the deposited compounds was completed. For the heat treatment tests, several surfaces with the same characteristics, surface 2 (described in Table 1), were produced and submitted to several resistive oven tests with different parameters, in order to obtain the parameter considered ideal for these surfaces. The results below present some of the parameters used, as well as the surfaces after heat treatment.

The first configuration tested in the resistive oven, heat treatment 1 , the heating heating process from ambient temperature to $200^{\circ} \mathrm{C}$ at a rate of $1^{\circ} \mathrm{C} / \mathrm{min}$, holding at $200^{\circ} \mathrm{C}$ for 5 hours and then cooling at the rate $1^{\circ} \mathrm{C} / \mathrm{min}$ from $200^{\circ} \mathrm{C}$ to ambient temperature inside the oven. Figure 5 shows the configuration used in the sintering process and the surface obtained.

Heat treatment 2, the heating process from ambient temperature to $100^{\circ} \mathrm{C}$ at a rate of $0.5^{\circ} \mathrm{C} / \mathrm{min}$; stay at $100^{\circ} \mathrm{C}$ for 20 minutes; heating from $100^{\circ} \mathrm{C}$ to $150^{\circ} \mathrm{C}$ at a rate of $0.5^{\circ} \mathrm{C} / \mathrm{min}$; holding at $150^{\circ} \mathrm{C}$ for 20 minutes; heating from $150^{\circ} \mathrm{C}$ to $200^{\circ} \mathrm{C}$ at a rate of $0.5^{\circ} \mathrm{C} / \mathrm{min}$; stay at $200^{\circ} \mathrm{C}$ for 5 hours; cooling from $200^{\circ} \mathrm{C}$ to ambient temperature inside the oven. Figure 6 shows the configuration used in the sintering process and the surface obtained.

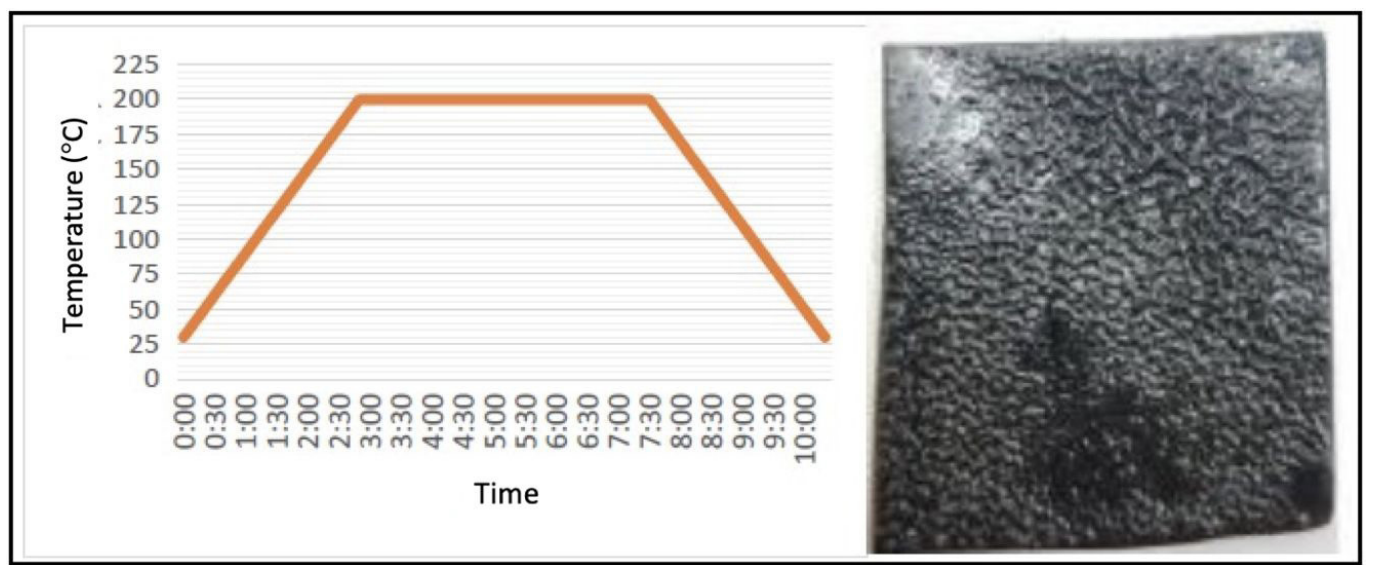

Figure 5. Thermal treatment 1.

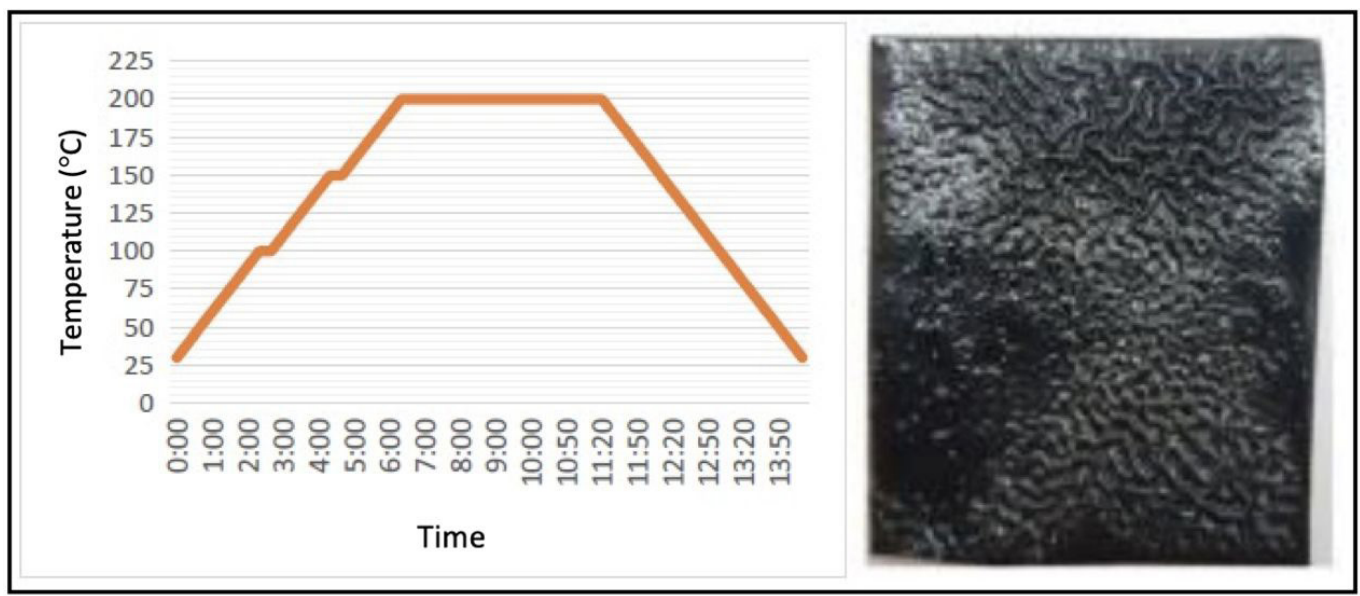

Figure 6. Thermal treatment 2 . 
For heat treatment 3 , the heating process from ambient temperature to $50^{\circ} \mathrm{C}$ at a rate of $0.5^{\circ} \mathrm{C} / \mathrm{min}$; stay at $50^{\circ} \mathrm{C}$ for 20 minutes; heating from $50^{\circ} \mathrm{C}$ to $100^{\circ} \mathrm{C}$ at a rate of $0.5^{\circ} \mathrm{C} /$ min; stay at $100^{\circ} \mathrm{C}$ for 20 minutes; heating from $100^{\circ} \mathrm{C}$ to $150^{\circ} \mathrm{C}$ at a rate of $0.5^{\circ} \mathrm{C} / \mathrm{min}$; stay at $150^{\circ} \mathrm{C}$ for 5 hours; cooling from $150^{\circ} \mathrm{C}$ to ambient temperature inside the oven. Figure 7 shows the configuration used in the sintering process and the surface obtained.

Several other heat treatments were performed with different configurations, however the surfaces obtained were similar to the surfaces presented in heat treatment 1 and 2 . In these thermal treatments ( 1 and 2 ) the surfaces showed corrugated aspects, since higher temperatures were used in them. The image of the sample, obtained with heat treatment 3 , shows that the use of these heating parameters resulted in a selective surface perfectly adhered to the metallic substrate, but it presents a rough appearance, possibly arising from the particle size of the CRFO.

\subsection{Characterization by $U V-V I S$}

Absorbance is an important property to be analyzed on a selective surface, as it is directly linked to the ability to absorb thermal energy. For this characterization, the Shimadzu spectrophotometer, UV-2600 was used. Figure 8 shows

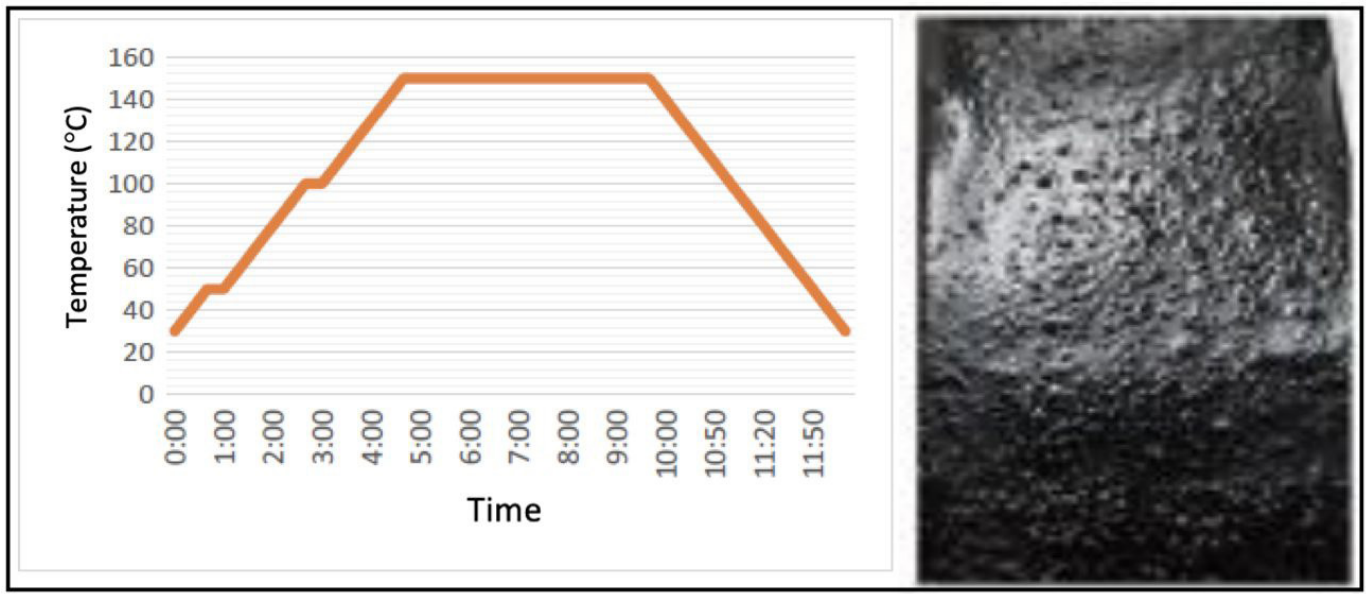

Figure 7. Thermal treatment 3.

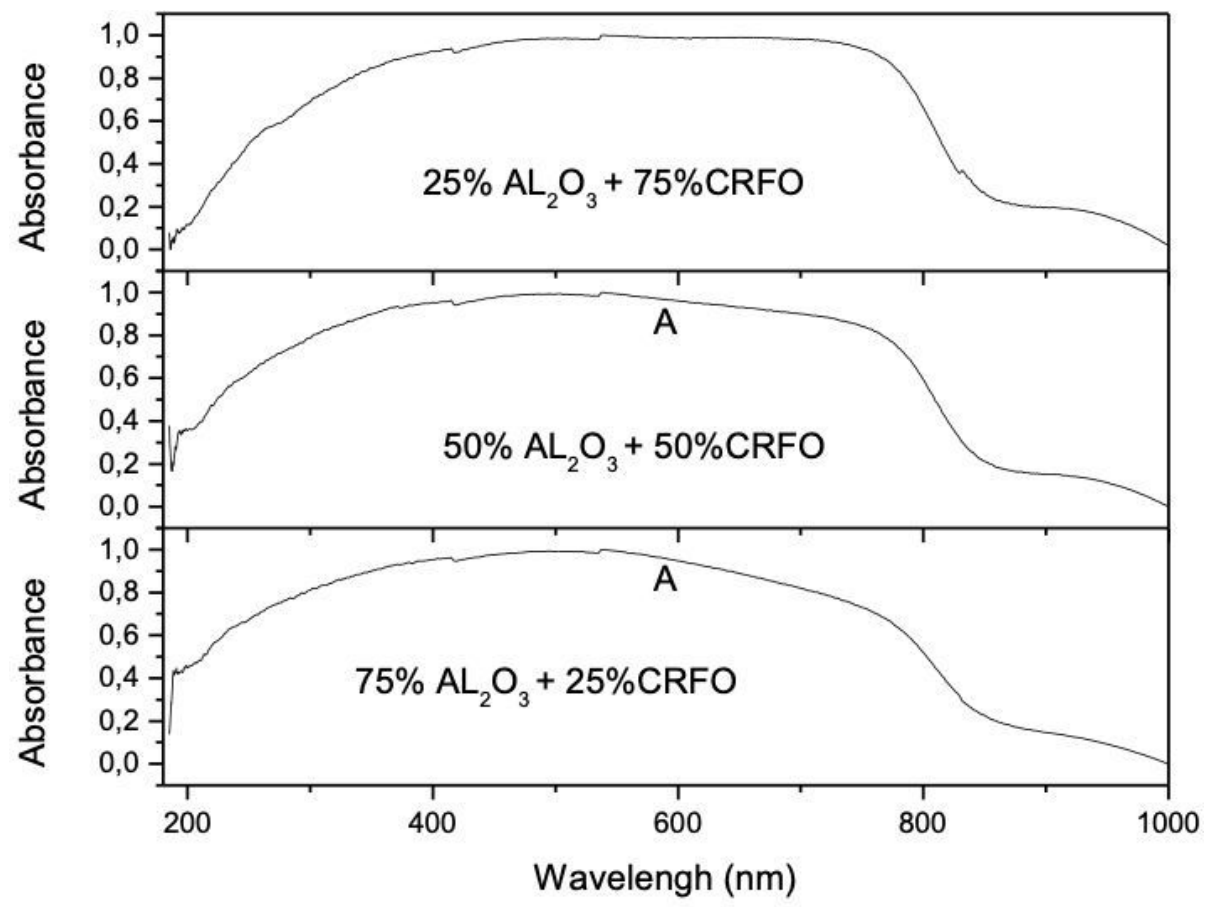

Figure 8. UV-VIS graph. 
the graph plotted from the results obtained for CRFO and aluminum oxide, according to the surfaces shown in Table 1.

It is observed that on the three surfaces, $25 \% \mathrm{AL}_{2} \mathrm{O}_{3}+75 \%$ CRFO, 50\% $\mathrm{AL}_{2} \mathrm{O}_{3}+50 \% \mathrm{CRFO}$ and $75 \% \mathrm{AL}_{2} \mathrm{O}_{3}+25 \%$ CRFO, the behavior is similar. The absorptivity in the visible light range (400 $\mathrm{nm}$ to $750 \mathrm{~nm}$ ) has a maximum value, which is a positive aspect for solar energy absorption. It is also verified that there is a tendency to fall after the visible light band, at approximately $750 \mathrm{~nm}$, showing a more accentuated fall in the composite surface of 75\% $\mathrm{AL}_{2} \mathrm{O}_{3}+25 \% \mathrm{CRFO}$.

It is possible to observe that the $25 \% \mathrm{AL}_{2} \mathrm{O}_{3}+75 \% \mathrm{CRFO}$ surface presented an average absorptivity value of 0.947 , in the visible light range, which is higher than the other samples. The samples CRFO, 50\% $\mathrm{AL}_{2} \mathrm{O}_{3}+50 \% \mathrm{CRFO}$ and $75 \% \mathrm{AL}_{2} \mathrm{O}_{3}+25 \%$ CRFO presented average absorptivity values of 0.937 and 0.933 respectively.

\subsection{Infrared analysis}

The purpose of conducting this characterization is to identify the emergence of any component after the heating process of the selective surfaces in resistive oven. Infrared analysis was proceeded with $\mathrm{KBr}$ pellets on Shimadzu IRTracer-100, range of $400-4000 \mathrm{~cm}^{-1}$.

Thus, the infrared analysis was performed before the deposition of the compound on the substrate (not deposited) and after the heat treatment (deposited) for the three surfaces defined in Table 1. Figure 9 presents the infrared analysis for the surfaces.

In Figure 9, five main peaks are observed, in the following frequency regions: $250-500 \mathrm{~cm}^{-1}$, approximately $1000 \mathrm{~cm}^{-1}$, $1500-2000 \mathrm{~cm}^{-1}, 2750-3000 \mathrm{~cm}^{-1}$ e approximately $3500 \mathrm{~cm}^{-1}$. In all samples, the shape of the peaks coincides with the non-deposited compound with the deposited compound, differing only in peak intensity, and no new components are obtained after heating.

\subsection{Analyzes in the SEM}

Through micrographs, obtained by SEM, it was possible to evaluate the arrangement of the composite material on the copper substrate, after completion of the heat treatment. The results of the micrographs are shown in Figures 10 to 12 with a magnification of $10000 x$ and 2000x, for the selective surfaces described in Table 1.

For the selective surface containing 25\% $\mathrm{AL}_{2} \mathrm{O}_{3}+75 \%$ CRFO, it is possible to verify exposed grains containing carbon, aluminum, chromium, iron and bismuth, the micrograph is shown in Figure 10. There is little unfilled space, the substrate almost entirely occupied.

For the selective surface containing 50\% $\mathrm{AL}_{2} \mathrm{O}_{3}+50 \%$ CRFO it is possible to verify exposed grains containing carbon, aluminum, chromium, iron and bismuth, the micrograph is shown in Figure 11. A large area of unfilled copper substrate is also observed.

For the selective surface containing $75 \% \mathrm{AL}_{2} \mathrm{O}_{3}+25 \%$ $\mathrm{CRFO}$, it is possible to verify exposed grains containing carbon, aluminum, chromium, iron and bismuth, the micrograph is shown in Figure 12. There is little unfilled space, the substrate being almost completely occupied. Carbon is observed on all selective surfaces, possibly from the MRAraldite.

In general, in Figures 10 to 12, it is possible to verify a sample with good deposition, since the grains spread on the surfaces are evenly spread.

\subsection{Field tests}

On April 19, 2021, the field test was conducted with temperature measurements of the selective surfaces, glass

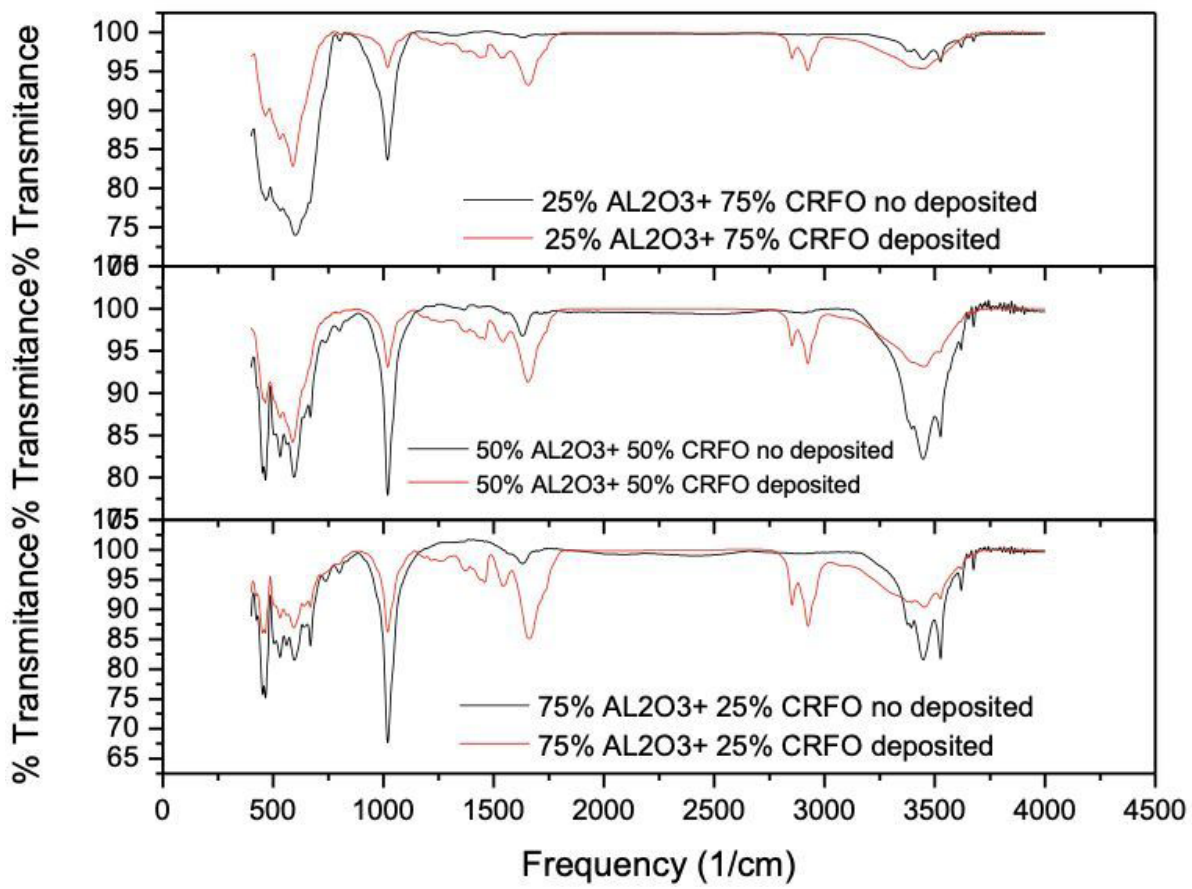

Figure 9. Sample transmittance graph. 

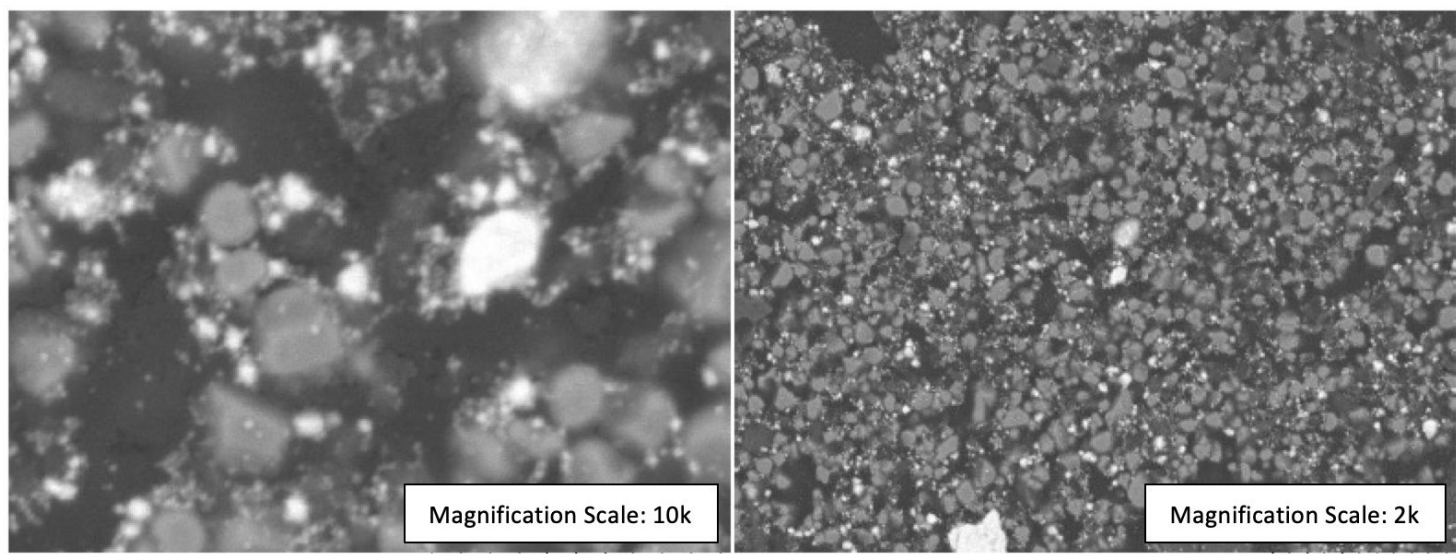

Figure 10. Micrograph of sample of $25 \%$ aluminum oxide - 75\% CRFO powder, with magnification of (a) 10,000x and (b) 2000x.
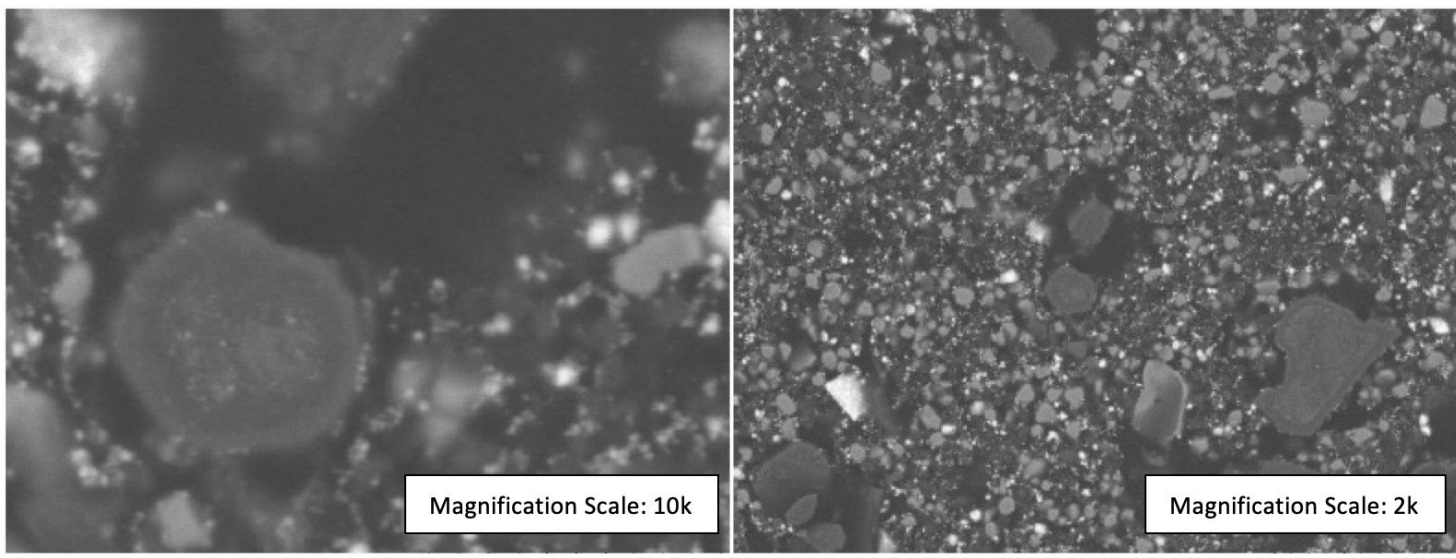

Figure 11. Micrograph of sample of 50\%aluminum oxide 50\% CRFO powder, with magnification of (a) 10,000x and (b) 2000x.

cover, environment and insulation. The test analyzed the behavior of the selective surfaces exposed to the sun.

The surfaces tested were: $25 \% \mathrm{AL}_{2} \mathrm{O}_{3}+75 \% \mathrm{CRFO}$, $50 \% \mathrm{AL}_{2} \mathrm{O}_{3}+50 \% \mathrm{CRFO}, 75 \% \mathrm{AL}_{2} \mathrm{O}_{3}+25 \% \mathrm{CRFO}$ and TiNOX. On this test day (April 19, 2021) the sky was clear with few clouds. The radiation presented a value of $1079,95 \mathrm{~W} / \mathrm{m}^{2}$ between 11:10 and 12:28, the interval in which the test bench was in operation. The temperature and global radiation measurements are shown in Figure 13.

The temperatures of the three surfaces were saved every 2 minutes. The temperatures of the selective surfaces, glass cover, insulation and environmental were measured and their averages are shown in Table 2.

To calculate the absorptivity, emissivity and efficiency from the energy balance described in section 2.4 , it was necessary to obtain data from the manufacturer of the commercial surface (MRTiNOX) and the glass used in the test bench. Manufacturer data are shown in Table 3.

To calculate the overall loss coefficient $\left(U_{l}\right)$ using the energy balance, Equation 9, was used the manufacturer's data together with the average radiation of $1020 \mathrm{~W} / \mathrm{m}^{\wedge} 2$ in the range in which the test bench was in operation. To obtain the heat transfer coefficient (h), was applied the Equation
Table 2. Average temperature.

\begin{tabular}{cc}
\hline Measured Elements & Average Temperature $\left({ }^{\circ} \mathrm{C}\right)$ \\
\hline $25 \% \mathrm{AL}_{2} \mathrm{O}_{3}+75 \% \mathrm{CRFO}$ & 69,4 \\
\hline $50 \% \mathrm{AL}_{2} \mathrm{O}_{3}+50 \% \mathrm{CRFO}$ & 68,9 \\
\hline $75 \% \mathrm{AL}_{2} \mathrm{O}_{3}+25 \% \mathrm{CRFO}$ & 70,1 \\
\hline MRTiNOX & 70,2 \\
\hline Glass Cover & 56,5 \\
\hline Insulation & 39,3 \\
\hline Environment & 39,2 \\
\hline
\end{tabular}

7 to the MRTiNOX surface data, knowing that the selective surface area is $A_{P}=0.0008 \mathrm{~m}^{2}$, the insulation thickness (L) is $5 \mathrm{~cm}$ and the thermal conductivity $(\mathrm{K})$ is $0.04 \mathrm{~W} / \mathrm{mK}$. The results obtained for the coefficients are shown in Table 4

For natural convection applications, the heat coefficient (h) can vary over a range of 5 to $30 \mathrm{~W} / \mathrm{m}^{2} \mathrm{~K}^{15}$. In this way, the result found presents values within the expected range.

As the overall coefficient of heat loss, obtained by the energy balance, was $U_{l}=19 \mathrm{~W} / \mathrm{m}^{2} K$, thus, the absorptivity values of the selective surfaces produced can be obtained using 

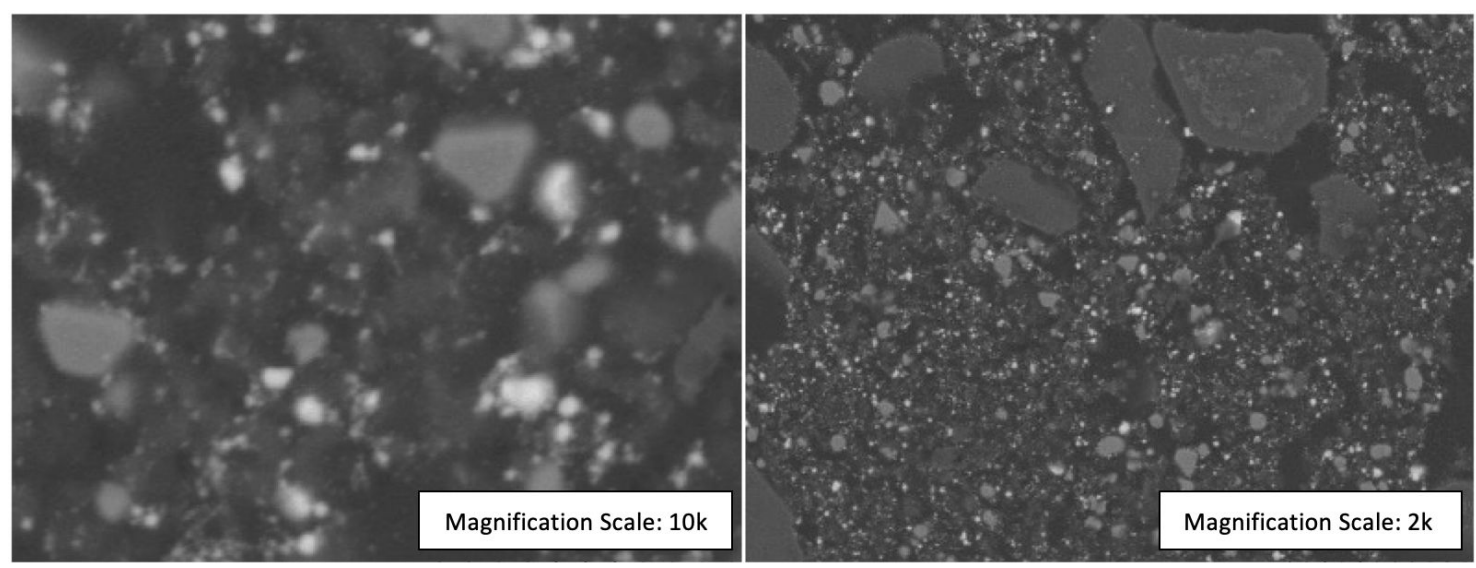

Figure 12. Micrograph of sample of $75 \%$ aluminum oxide - 25\% CRFO powder, with magnification of (a) $10,000 x$ and (b) 2000x.

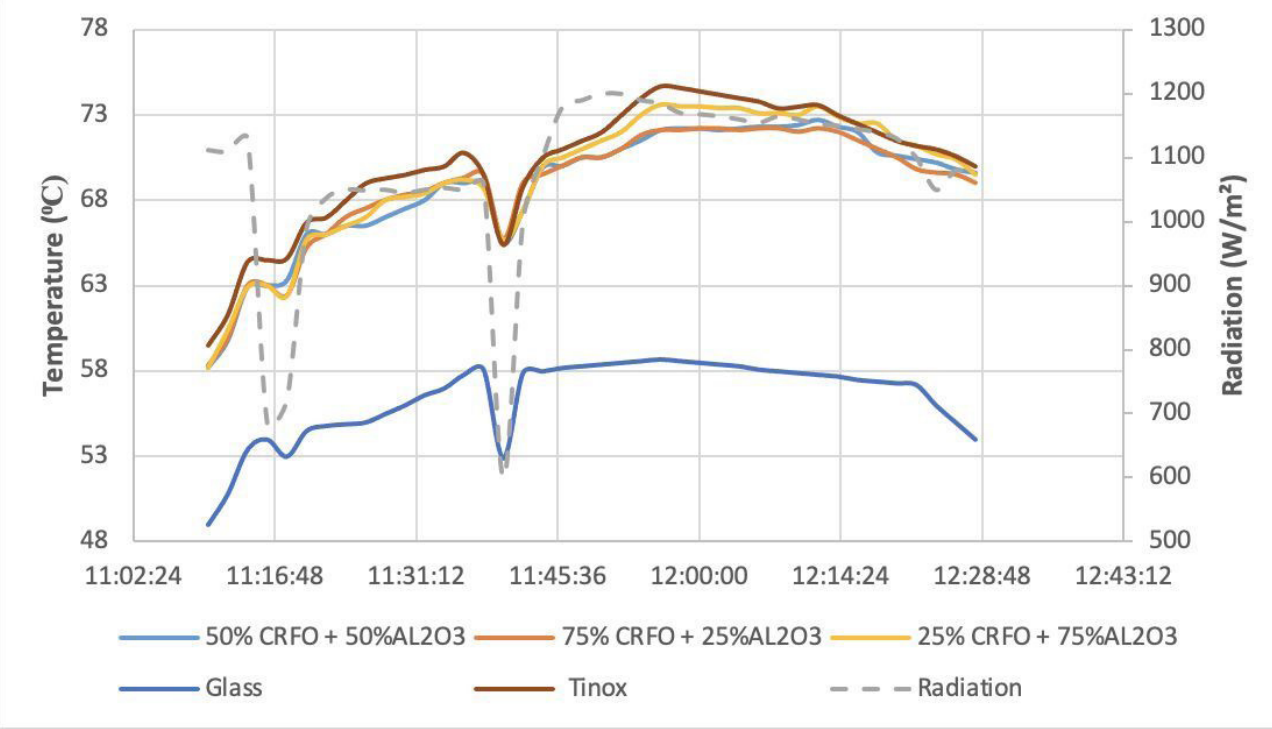

Figure 13. Results of the field test.

Table 3. Manufacturer`s data ${ }^{14}$.

\begin{tabular}{ccc}
\hline Materials & \multicolumn{2}{c}{ Properties } \\
\hline & Absorptivity $\left(\alpha_{s}\right)$ & Emissivity $(\varepsilon)$ \\
\hline MRTiNOX & 0.95 & 0.04 \\
\hline \multicolumn{2}{c}{ Transmissividade $\left(\tau_{v}\right)$} \\
\hline Vidro & \multicolumn{2}{c}{0.87} \\
\hline
\end{tabular}

Equation 9. Using Equation 7, with the values of absorptivity, the emissivity values were obtained. The efficiency (f) of the surfaces can be evaluated dividing the absorptivity by the emissivity. For efficiency values greater than 18 ( $\mathrm{f}>18$ ), the surface is considered highly selective ${ }^{16}$. The results obtained are shown in Table 5.

The efficiency of the $25 \% \mathrm{AL}_{2} \mathrm{O}_{3}+75 \%$ CRFO surface was higher than that of the other surfaces, including the commercial MRTiNOX, because although it had lower absorptivity, it had a lower emissivity value, which increased
Table 4. Results obtained for the coefficients.

\begin{tabular}{cc}
\hline Coefficient & Results obtained \\
\hline Overall loss coefficient $\left(U_{l}\right)$, & 19 \\
\hline Heat transfer coeficiente $(\mathrm{h})$ & $27.9 \frac{\mathrm{W}}{\mathrm{m}^{2} \mathrm{~K}}$ \\
\hline
\end{tabular}

its efficiency. The average surface temperature $25 \%$ $\mathrm{AL}_{2} \mathrm{O}_{3}+75 \%$ CRFO, shown in Table 2 , is very close to the average of the commercial surface MRTiNOX and there is an oscination of these values in Figure 13, which is due to the proximity of the absorbance values and emittance of these two surfaces. The CRFO, 50\% $\mathrm{AL}_{2} \mathrm{O}_{3}+50 \%$ CRFO and $75 \% \mathrm{AL}_{2} \mathrm{O}_{3}+25 \% \mathrm{CRFO}$ surfaces had lower efficiency and absorptivity values and higher emissivity values, but still considered high. 
Table 5. Absorptivity and emissivity of selective surfaces.

\begin{tabular}{cccc}
\hline Surface & Absorptivity & Emissivity & Efficiency \\
\hline $25 \% A L_{2} O_{3}+75 \%$ CRFO & 0.935 & 0.043 & 21,74 \\
\hline $50 \% A L_{2} O_{3}+50 \%$ CRFO & 0.935 & 0.048 & 19,48 \\
\hline $75 \% A L_{2} O_{3}+25 \%$ CRFO & 0.94 & 0.0379 & 24,80 \\
\hline MRTiNOX & 0.95 & 0.04 & 23,75 \\
\hline
\end{tabular}

\section{Conclusions}

The selective surface obtained after performing the tests described in this study, showed satisfactory visual appearance, low thickness deposited with good adhesion to the metal substrate. It was also verified that the selective surfaces produced, based on the achieved results, obtained similar results to the commercial surface MRTiNOX, mainly for the absorptivity values, in the field test. It is observed that in the results obtained in the characterization by UVVIS, the absorptivity showed high values in the visible light range, demonstrating an assertive characteristic for capturing solar energy. Therefore, the selective surfaces produced can be a technically viable alternative in thermal solar-thermal collectors.

\section{References}

1. Blaschke T, Biberacher M, Gadocha S, Schardingere I. Energy landscapes: meeting energy demands and human aspirations. Biomass Bioenergy. 2013;55:3-16. http://dx.doi.org/10.1016/j. biombioe.2012.11.022.

2. Duffie JA, Beckman WA. Solar engineering of thermal processes. Philadelphia: Wiley; 2013.

3. Medeiros ID, Gomes KC, Gonçalves RP, Galvão GO. Selective solar surface solar based on black chromium: influence of electrodeposition parameters in the absorption of surfaces. Mater Res. 2019;22(2):1-6. http://dx.doi.org/10.1590/19805373-MR-2018-0625.

4. Teixeira V, Sousa E, Costa MF, Nunes C, Rosa L, Carvalho $\mathrm{MJ}$, et al. Spectrally selective composite coatings of $\mathrm{Cr}-\mathrm{Cr} 2 \mathrm{O} 3$ and Mo-Al2O3 for solar energy applications. Thin Solid Films. 2001;392:320-6. http://dx.doi.org/10.1016/S0040-6090(01)010513.

5. Banthuek S, Suriwong T, Nunocha P, Andemeskel A. Application of Ni-A12O3 cermet coating on aluminium fin a the solar absorber in evacuated tube collector (ETC). Mater Today. 2018;5(7):14793-8. http://dx.doi.org/10.1016/j.matpr.2018.04.007.

6. Freire FN. Síntese e estudo das propriedades estruturais e dielétricas de matrizes cerâmicas compósitas (CMC) baseadas em: (Fe1/4 Cu3/8 Ti3/8)2O3 / (Fe5/8Cr3/8)2O3 / Pb(Fe1/2

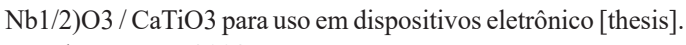
Fortaleza: UFC; 2008.

7. Nunes RA, Costa VC, Costa WC, Araújo FR, Silva GM. Mater. Res. Selective Surfaces of Black Chromium for Use in Solar Absorbers. 2017;21:1-5. http://dx.doi.org/10.1590/1980-5373MR-2017-0556.

8. Souza AP, Cavalcante NM, Freire FN, Almeida AF. Performance evaluation of titanium oxide deposited by electrophoresis in photoelectrodes of dye-sensitized solar cells. Materia (Rio J). 2021;26(1):e12951. http://dx.doi.org/10.1590/S1517707620210001.1251 .

9. Vieira SG. Obtenção, caracterização e aplicação de uma nova superfície seletiva para coletores solares térmicos [dissertation]. Fortaleza: UFC; 2011.

10. Rodrigues FP. Obtenção e estudo de uma superfície seletiva para coletores solares térmicos a partir de resíduos de granito [dissertation]. Fortaleza: UFC; 2014.

11. Araújo FA, Freire FN, Pinho DC, Dutra KH, Rocha PA, Silva ME. Study of surfaces, produced with the use of granite and titanium, for aplications with solar thermal collectors. Rev Adv Mater Sci. 2021;60:47-56. http://dx.doi.org/10.1515/ rams-2021-0005.

12. Araújo FA, Freire FN, Pinho DC, Dutra KH, Rocha PA, Silva ME. Characterization of new selective coatings, made of granite and chrome, for solar collectors. Materia (Rio J). 2019;24(2):114. http://dx.doi.org/10.1590/S1517-707620190002.0694.

13. Pinho DC, Freire FN, Araújo FA, Dutra KH, Teixeira ES, Silva MV, et al. Proc. Characterization and application of a selective coating for solar collectors from of the cashew nut shell liquid. Inst Mech Eng, Part L: J Mater. Des Appl. 2019;234:167-74. http://dx.doi.org/10.1177/1464420719880935.

14. Almeco Group. Tinox Energy: Solar absorber coatings. [Internet]. Bernburg, Germany: Amtsgericht Stendal; 2020 [cited 2021 Aug 20]. Available from: https://www.almecogroup.com/uploads/ generic_file/ALMECO_TinoxEnergy_EN-S402-022020_mail_2. pdf.

15. Incropera FP, Witt DP, Bergman TL, Lavine AS. Fundamentals of heat ans mass transfer. Hoboken: Wiley; 2006.

16. Kalogirou SA. Prediction on flat-plate collector performance parameters using artificial neural networks. Sol Energy. 2006;80:248-59. http://dx.doi.org/10.1016/j.solener.2005.03.003. 